\title{
Comparison of Aerodynamic Characteristics During Reading Paragraph Tasks in Normal Male and Female Adults
}

\author{
Hwa-Young Pyo \\ Department of Speech and Language Pathology, College of Natural Science, Public Health and Safety, Chosun University, Gwangju, Korea
}

\author{
Received: August 31, 2020 \\ Revised: September 26, 2020 \\ Accepted: October 13, 2020 \\ Correspondence: \\ Hwa-Young Pyo, PhD \\ Department of Speech and \\ Language Pathology, \\ College of Natural Science, \\ Public Health and Safety, \\ Chosun University, \\ 309 Pilmun-daero, Dong-gu, \\ Gwangju 61452, Korea \\ Tel: +82-62-230-6188 \\ Fax: +82-62-230-6172 \\ E-mail: entvoice@chosun.ac.kr
}

\begin{abstract}
Purpose: The present study was performed to compare the aerodynamic characteristics of males and females during reading paragraph task. Methods: Thirty-seven normal adult males (18-30 yrs) and thirty-nine normal adult females (18-34 yrs) were participated in this experiment. They read a part of 'Gaeul' paragraph with comfortable phonation, and the reading samples were recorded and analyzed by 'Running Speech' program of Phonatory Aerodynamic System (PAS). Results: Phonation time (with voicing) and expiratory airflow duration were significantly longer in females, but measures of inspiratory airflow duration, peak expiratory airflow, expiratory and inspiratory volumes were significantly higher in males. The difference in total duration and peak inspiratory airflow did not show statistical significance. Conclusion: Results revealed that there was a significant gender difference in aerodynamic measures of duration and airflow during the reading paragraph task. In evaluating and intervening aerodynamics of voice and voice disorder patients, we should also consider the gender-different aerodynamic characteristics in continuous speech.
\end{abstract}

Key Words: Aerodynamic evaluation, Airflow, Duration, Gender difference, Reading paragraph.

\section{INTRODUCTION}

Ferrand(2012)는 음성장애 환자를 평가할 때 언어재활사 (speech language pathologist, SLP)는 다양한 방법으로 음성 의 음도, 강도, 음질 특징을 평가하고 다양한 상황의 음성산출 방법이나 습관 등을 평가하며 이비인후과 의사는 내시경을 이 용하여 환자의 성대 및 후두를 검사함으로써 후두의 구조적 병 리 혹은 기능의 문제를 발견한다고 하였다. 이와 같이 음성장 애 환자의 음성 평가에 있어 주로 SLP는 음성과 음성산출에, 의사는 성대 해부생리의 병리적 측면에 초점을 맞춘다. 이를 위 해 SLP는 음향적 평가, 공기역학적 평가, 성대진동 검사 등의 기기적 평가와 청지각적 평가를 통해 환자의 음성 상태를 확인 하고 음성산출의 정상성 여부를 판단한다.

공기역학적 평가는 발화 시 적절한 호흡지지가 이루어지는 시간과 정도를 파악하여 편안한 음성산출을 어느 정도 유지할 수 있는지 알아보고자 시행된다. 발화 시 호흡지지는 음성산출 방법에 중요한 영향을 미치기 때문에 공기역학적 평가는 환자

(cc) This is an Open Access article distributed under the terms of the Creative Commons Attribution Non-Commercial License (https://creativecommons.org/licenses/by-nc/4.0) which permits unrestricted non-commercial use, distribution, and reproduction in any medium, provided the original work is properly cited.
의 음성 특성뿐 아니라 평소의 음성산출 습관을 파악하는 데 도 중요한 정보를 제공하고 음성산출과 관련된 해부생리학적 특징의 단서도 제공한다(Goozée et al., 1998; Schaeffer, 2017). 이 때문에 공기역학적 평가는 음성의 기기적 평가 시 기본적으 로 사용하는 평가방법 중 하나이다.

공기역학적 평가와 같은 기기적 평가를 시행할 때 어떤 과제 를 사용하여 어떤 음성샘플을 분석자료로 사용할 것인가는 Gerratt et al.(2016)이 언급한 것처럼 여전히 논쟁의 여지가 있 는 주제이며, 쉽게 결정할 수 없는 난제 중 하나이다. 특히 기기 를 이용한 평가는 기기가 분석할 수 있는 범위에 맞춰 음성샘 플을 취해야 하므로 평가자가 임의로 음성샘플을 선정할 수 없 기 때문에 더욱 그렇다. 과거에는 대부분의 음성분석기기가 연 장모음 산출을 분석재료로 하였다. 유도하기 쉽고 인접한 음소 의 영향을 받지 않는 장점 때문에 널리 선호되어왔으나(Gerratt et al., 2016) 일상생활에서 연장모음을 산출할 일이 흔하지 않 은 만큼 항상 일상생활 시 음성사용과의 괴리가 문제점으로 지 적되었다. Maryn \& Roy(2012)도 숙련된 청취자로 하여금 39명 의 음성장애 환자의 연장모음과 연속발화에 대한 음성문제의 중증도를 평정하도록 한 결과 같은 화자의 발화여도 연장모음 의 중증도를 연속발화보다 더 문제가 심각한 것으로 평정했다 
고 보고하였다. 그러므로 연장모음 과제만으로 일상생활에서 사용되는 연속발화의 특징을 파악하기는 어렵다.

최근에는 다양한 분석방법이 제기되면서 기기적 평가에도 연속발화를 사용하는 방법이 꾸준히 제시되고 있다. 음향적 평 가에서 켑스트럼 분석(cepstral analysis)을 통해 연속발화 시 음질을 분석하는 것이 대표적이며 공기역학적 평가에서도 연속 발화 시 지속시간 및 기류관련 분석을 통해 연속발화 시 공기 활용에 대한 분석을 실시하고 있다. Dastolfo et al.(2016)과 Lewandowski et al.(2018) 등도 연속발화 시 공기역학적 특성 에 대해 분석한 연구결과를 발표했고 국내에서도 다양한 집단 을 대상으로 문단 낭독에 의한 연속발화 시 공기역학적 특성을 비교한 연구결과가 보고되었다. Han et al.(2008)은 정상 성대 를 가진 정상성인(이하 정상성인 혹은 정상 화자) 여성 화자를 대상으로 연속발화 시 공기역학적 특성을 분석했고, Moon et al.(2019)은 정상 화자와 음성장애 화자, 음성장애 화자의 수술 전후 연속발화 시 공기역학적 특성을 비교했으며, $\mathrm{Pyo}(2019 \mathrm{a})$ 는 음성장애 화자 중 젊은 성인 환자와 노인 환자를 대상으로 연속발화 시 공기역학적 특성을 비교하여 보고했다. 그러나 문 단을 낭독할 때 공기역학적 특성이 성별에 따라 어떤 차이를 보 이는지 비교한 연구는 아직 찾아보기가 어렵다.

연구마다 차이가 있기는 하지만 음성산출 시 공기역학적 특 성은 성별에 따라 차이를 보이며 남성이 여성보다 더 높은 기류 량과 발성 지속시간을 보인다는 것이 일반적이다. 그러나 이는 대부분 연장모음 과제를 분석한 결과로서 문단낭독 시에도 이 러한 성차가 나타날지에 대한 연구는 아직도 부족하다. 이에 본 연구에서는 정상성인을 대상으로 문단 낭독 시 남성과 여성 이 공기역학적 측정치에서 유의한 차이를 보이는지 알아보고 자 하였다. 이를 통하여 연속발화 시 공기역학적 평가결과를 해 석하고 그 결과를 바탕으로 중재계획을 수립할 때 성별에 따른 차이를 어느 정도로 고려해야 하는지 고찰해보고자 한다.

\section{MATERIALS AND METHODS}

\section{연구 대상}

본 연구에는 최근 1 개월 이내 음성 및 음성에 영향을 줄 만 한 문제가 없었다고 보고한 18 세 이상의 정상성인 남성 37 명, 여성 39명이 연구자가 발송한 이메일을 직접 확인했거나 이메 일을 확인한 친구들의 소개를 받고 연구에 자발적으로 참여하 였다. 이들은 1) 최근 1 개월 이내 음성 문제나 감기, 알레르기성 비염, 호흡기 질환 등 음성에 영향을 미칠 만한 병력이 없었고, 2) 현재 3일 이상 복용 중인 약물이 없으며, 3) 음성장애를 포 함한 의사소통장애를 동반하지 않고, 4) 읽기 문제, 시각 및 청 각의 문제, 인지 문제를 동반하지 않아 지시에 따라 문단낭독
과제를 수행하는 데 문제가 없었고, 5) 성악가 등 직업적 음성 사용인이거나 음성 및 발성에 대한 전문적 훈련을 받은 경험이 없고, 6) 음성장애 평가 및 연구경력 20년 이상의 음성장애 전 문가 1 인과 음성장애 전공 대학원생 2 인이 시행한 청지각적 평 가 결과 정상 음성을 산출하는 것으로 판단되었다. Manifold \& Murdoch(1993)이 60명의 젊은 성인을 대상으로 실험한 결과 발화 시 공기역학적 특성에 체격은 유의한 영향을 미치지 않는 다고 한 보고에 따라 체격은 선정기준으로 고려하지 않았다.

남성 참여자 37명의 평균연령은 22.84세(18 30세, SD: 2.49), 여성 참여자 39명의 평균연령은 21.62세(18 34세, SD: 4.27)였 으며 두 군 간의 연령은 독립표본 $t$-검정 결과 유의한 차이가 없 는 것으로 나타났다 $(t=1.993, p>0.05)$.

\section{연구 절차}

본 연구의 실험 절차는 본 연구자의 선행연구(Pyo, 2019a, 2019b)에서 시행된 실험절차에 기초하여 진행되었다. 실험에 사 용된 기자재는 Phonatory Aerodynamic System (PAS, model No. 6600; KayPENTAX, Montvale, NJ, USA)이었으며 연구 에 사용한 공기역학적 평가 프로그램은 Running Speech였다. Running Speech 프로그램은 문단낭독 시 발성지속시간, 호기 및 흡기지속시간 등의 지속시간 관련 정보와 최대호기량 및 흡 기량, 호기 및 흡기체적 등 기류량 관련 정보를 제공해준다.

실험은 대학교 실습센터 내 설치된 음성분석실에서 실습이 없는 조용한 시간에 이루어졌다. 참여자들은 실험 시작 전 연 령, 병력 등 개인정보를 기록지에 기록한 후 실험 과정 및 참여 방법에 대한 사전설명을 들었다.

실험에 사용한 낭독재료는 $\operatorname{Kim}(2017)$ 의 '가을' 문단 중 일부 로 Appendix 1에 제시하였다. 이는 아래아 한글 문서에서 글자 크기 17 포인트, 줄간격 $250 \%$ 로 작성하여 가로방향으로 인쇄 한 후 코팅하여 참여자에게 제공되었다. 참여자는 실험을 위한 낭독 전에 낭독재료를 미리 눈으로 읽어봄으로써 내용에 친숙 하게 하였다. 검사자의 지시에 따라 검사용 마스크를 얼굴에 밀 착시킨 후 평소에 책을 읽듯이 편하게 문단을 낭독하도록 하였 다. 1 회 낭독을 원칙으로 하였으나 낭독 시 나타난 실수가 3 회 이상 반복될 경우 다시 한 번 읽도록 하였다. 2회 낭독 후에도 3 회 이상 낭독 실수가 나타난 경우는 분석대상에서 제외하였다.

\section{자료 및 통계 분석}

문단낭독 시 공기역학적 특성 분석은 검사 전 흡연 혹은 탄 산음료를 섭취했거나 3회 이상 낭독 실수가 반복된 경우를 제 외한 후 최종적으로 남성 37명, 여성 39명 총 76명의 낭독자료 를 대상으로 실시하였다. 본 연구에서 분석한 측정치는 모두 8 개인데 이중 7 개는 참여자가 낭독한 문단 전체구간을 분석대상 
으로 설정한 후 Running Speech 프로그램의 Analysis 메뉴를 이용하여 자동으로 도출한 측정치이다. 여기 해당하는 7 개 측 정치는 발성지속시간(phonation time), 호기지속시간(expiratory airflow duration), 흡기지속시간(inspiratory airflow duration), 최대호기량(peak expiratory airflow), 최대흡기량 (peak inspiratory airflow), 호기체적(expiratory volume), 흡기 체적(inspiratory volume)이다. 이 측정치에 대한 설명은 $\mathrm{Ap}-$ pendix 2에 제시하였다. 나머지 1개 측정치는 본 연구자가 추가 로 계산한 총발화지속시간(total duration)으로 이는 흡기지속 시간과 호기지속시간의 합으로 구하였다. Running Speech 프 로그램에서 제공하는 발성지속시간은 성대진동이 유지된 시간 만을 포함하고 있으므로 성대진동이 없는 무성음이나 휴지 구 간은 제외하고 있다. 따라서 이 측정치로는 화자가 210 개 음절 의 문단자료 전체를 낭독하는 데 걸린 전체 지속시간을 파악할 수 없으므로 발화 시 호기 및 흡기가 지속된 전체구간을 총발 화지속시간으로 하여 따로 구하였다. 이에 대한 설명도 $\mathrm{Ap}^{-}$ pendix 2에 추가하였다.
각 측정치의 기술 및 추론통계는 SPSS (25.0 version, IBM Corp., Armonk, NY, USA)를 이용하여 이루어졌다. 전체 측정 치의 평균 및 표준편차를 구하였고 남성군 및 여성군 측정치 차이의 유의성은 독립표본 $t$-검정을 통해 검증하였다.

\section{RESULTS}

정상성인 남성군 및 여성군 76 명이 210개 음절의 문단자료를 낭독한 전체 구간을 대상으로 Running Speech 프로그램을 통 해 분석한 공기역학적 측정치의 평균 및 표준편차를 Table 1에 제시하였다. 문단 낭독 시 Running Speech 프로그램의 화면에 나타난 기류량의 변화를 보여주는 그래프를 Figure 1, 2에 제 시했는데 Figure 1은 남성군의 일례이고 Figure 2는 여성군의 일례이다.

지속시간과 관련된 네 개 측정치에서는 총발화지속시간을 제외한 발성지속시간과 호기 및 흡기지속시간이 유의한 성차 를 보였다. 발성지속시간과 호기지속시간은 여성군이 유의하게

Table 1. Results of aerodynamic measurement during paragraph reading

\begin{tabular}{|c|c|c|c|c|}
\hline & Males $(\mathrm{n}=37)$ & Females $(\mathrm{n}=39)$ & $t$ & $p$ \\
\hline PT (sec) & $22.97(2.05)$ & $26.80(2.17)$ & $-7.901^{* * *}$ & $2 \mathrm{E}-11$ \\
\hline $\mathrm{EAD}(\mathrm{sec})$ & $29.92(2.77)$ & $31.95(2.56)$ & $-3.322^{* *}$ & 0.001 \\
\hline IAD (sec) & $7.56(1.84)$ & $6.54(1.40)$ & $2.734^{* *}$ & 0.008 \\
\hline $\mathrm{TD}(\mathrm{sec})$ & $37.48(3.95)$ & $38.49(3.43)$ & -1.186 & 0.239 \\
\hline PEA (L/sec) & $0.96(0.32)$ & $0.53(0.15)$ & $7.658^{* * *}$ & $5.73 \mathrm{E}-11$ \\
\hline PIA (L/sec) & $-1.94(0.58)$ & $-1.82(0.32)$ & -1.086 & 0.281 \\
\hline EV (L) & $4.87(2.20)$ & $3.90(1.39)$ & $2.315^{*}$ & 0.023 \\
\hline IV (L) & $-4.63(1.76)$ & $-3.46(1.00)$ & $-3.597 * * *$ & 0.000 \\
\hline
\end{tabular}

Values are mean (SD). ${ }^{*} p<0.05,{ }^{* *} p<0.01,{ }^{* * *} p<0.001 . \mathrm{PT}$ : phonation time, EAD: expiratory airflow duration, IAD: inspiratory airflow duration, TD: total duration, PEA: peak expiratory airflow, EV: expiratory volume, PIA: peak inspiratory airflow, IV: inspiratory volume

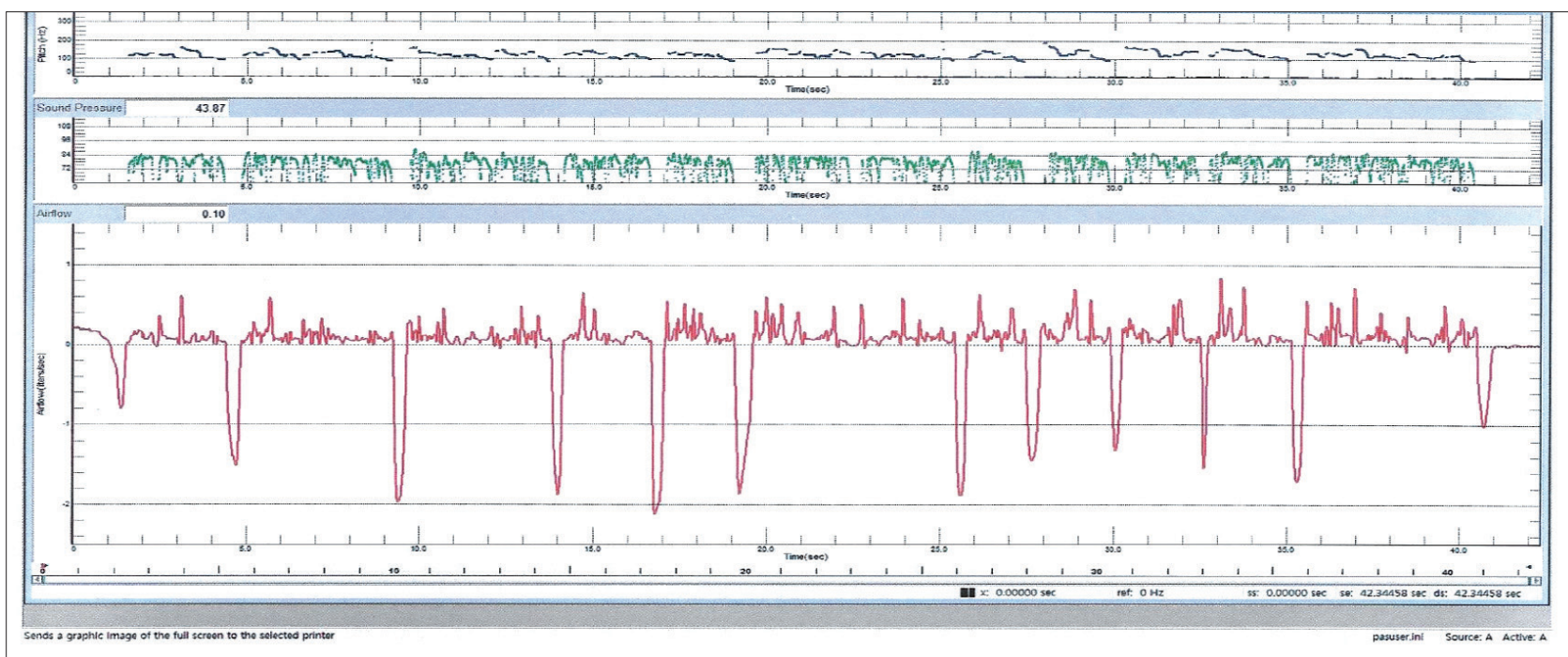

Figure 1. Running Speech display after paragraph reading (male). 


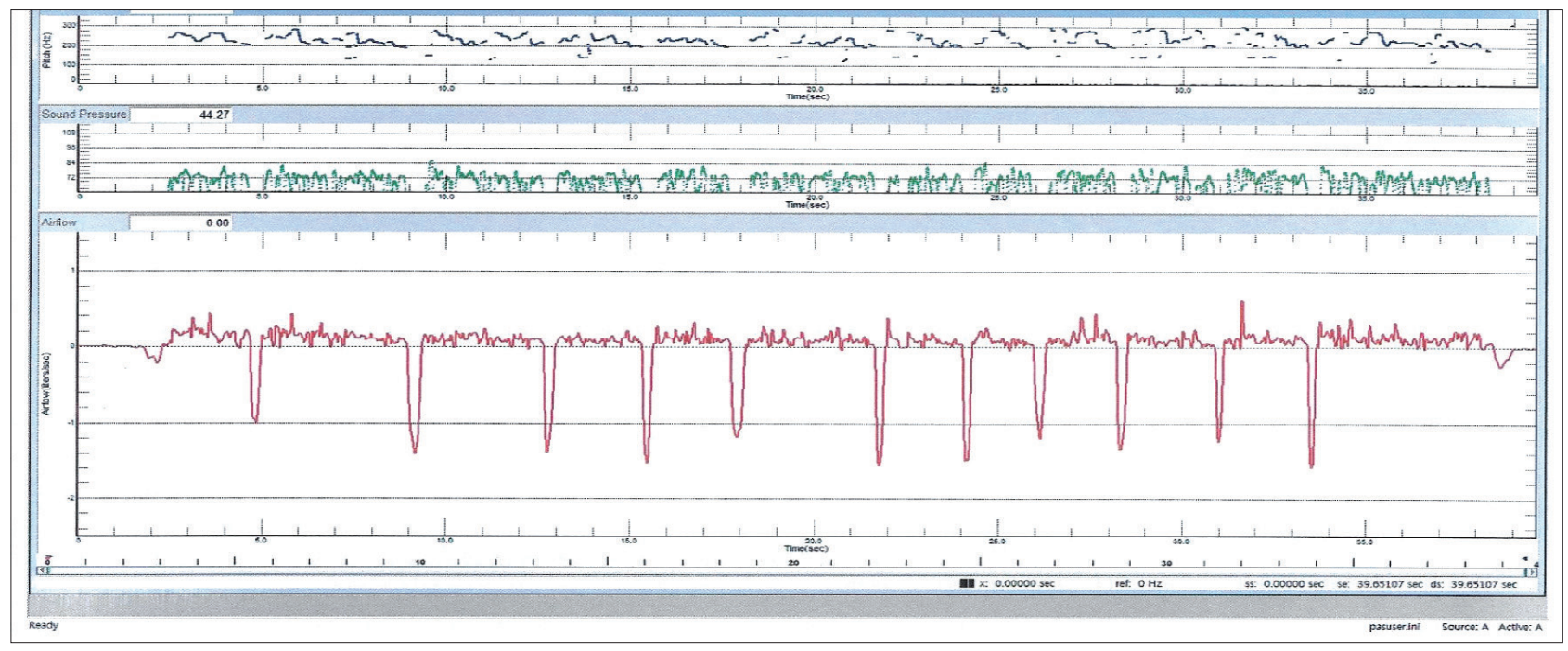

Figure 2. Running Speech display after paragraph reading (female).

더 길었던 반면 흡기지속시간은 남성군이 유의하게 더 길었다. 총발화지속시간은 여성군이 더 길었으나 유의한 차이는 나타 나지 않았다. 지속시간 관련 측정치 네 개 중 세 개에서 여성군 이 더 높은 수치를 보여 대체로 여성군의 지속시간이 남성군보 다 더 길었다.

기류량과 관련된 네 개 측정치 중 남성군의 최대흡기량이 여 성군보다 더 높은 수치를 보였으나 그 차이는 유의하지 않았다. 최대호기량, 호기체적 및 흡기체적도 남성군의 측정치가 여성 군보다 더 높게 나타났는데 이 차이는 통계적으로 유의하였다. 기류량 관련 측정치는 네 개 모두 남성군이 더 높은 수치를 보 여 문단낭독 시 남성군이 여성군보다 더 높은 수치의 기류량을 사용한 것으로 나타났다.

\section{DISCUSSIONS}

본 연구는 정상성인을 대상으로 문단낭독 시 공기역학적 특 성에서 성별에 따른 차이가 나타나는지 알아보고자 실시되었다. 남성군 37명, 여성군 39명을 대상으로 PAS의 Running Speech 프로그램을 이용하여 문단낭독 시 공기역학적 측정치를 비교 한 결과 발성지속시간과 호기지속시간에서는 유의하게 여성군 이 더 높은 수치를 보였고 흡기지속시간과 최대호기량, 호기 및 흡기체적은 유의하게 남성군이 더 높은 수치를 보였다. 총발화 지속시간은 여성군이, 최대흡기량은 남성군이 더 높은 수치를 보였지만 그 차이가 유의하지는 않았다.

지속시간 관련 측정치 중 총발화지속시간은 유의하지는 않 았으나 남성군 평균 37.48초, 여성군 38.49초로 여성군이 더 길 었다. 호기지속시간과 흡기지속시간의 합으로 전체 문단을 낭 독하는 데 소요된 시간을 의미하는 총발화지속시간이 성별간
차이가 유의하지 않았다는 것은 청년층 집단의 경우 동일한 길 이의 문단을 읽을 때 낭독 속도는 성별에 따른 차이가 크지 않 음을 의미한다.

발성지속시간은 성대진동이 동반되었을 때의 발화지속시간 을 의미한다. Gartner-Schmidt et al.(2015)은 연속발화 시의 기류 분석 시 성대가 진동하는 동안의 데이터를 분석하는 방법 에 대해 언급하였다. 연속발화 중에는 구어 산출에 의한 호기 류뿐 아니라 비구어적인 호기류 배출의 가능성도 있기 때문에 전체발화의 기류를 관찰하는 것보다 성대진동 구간의 기류를 분석하는 것이 더 좋다고 하였다. Running Speech 프로그램에 서는 성대진동 구간의 지속시간을 발성지속시간으로 따로 제시 하고 있는데 본 연구결과 8개 측정치 중 성별 간 유의한 차이가 나타난 6 개 측정치 중에서도 발성지속시간의 차이값이 가장 크 게 나타났다. 이는 성대진동 구간의 기류 측정치가 성별 간의 차이를 잘 보여주고 있다고 한 위의 연구결과와 맥락을 같이 한 다. 다만 Running Speech에서는 성대진동구간의 지속시간은 제시하고 있으나 기류량은 제시하지 않고 있어 이에 대한 비교 는 할 수 없었다.

총발화지속시간은 남성군과 여성군에서 비슷하게 나타났고 둘 다 호기지속시간이 흡기지속시간보다 더 길었다. 남성군은 총발화지속시간 평균 37.48초 중 호기지속시간과 흡기지속시간 의 비율이 $79.8 \%$ 대 $20.2 \%$ 였고 여성군은 총발화지속시간 평균 38.49 초 중 두 지속시간의 비율이 $83.0 \%$ 대 $17.0 \%$ 였다. 여성군 의 흡기지속시간은 남성군보다 더 짧았고 총발화지속시간 중 흡 기지속시간의 비율도 남성군보다 더 짧았다. Yoo \& Shin(2019) 은 청년층 남성군 및 여성군 24명을 대상으로 문단낭독 시 휴 지길이 및 빈도를 분석한 결과 들숨을 동반한 휴지의 길이는 유의하게 여성이 더 짧았다고 보고했다. 들숨을 동반한 휴지 길 
이와 같은 개념의 측정치가 본 연구에서는 흡기지속시간이라고 볼 수 있는데 본 연구의 흡기지속시간도 여성군이 유의하게 더 짧게 나타나서 이들의 연구와 일치하는 결과를 보였다. Yoo \& Shin(2019)은 이를 신체적 특성의 차이로 설명하여 여성이 남성 에 비해 폐용량이 작아 더 얕고 짧은 숨을 쉬기 때문으로 보았 다. 이러한 해석은 다른 선행연구와도 일치한다. Hodge \& Rochet(1989)은 여성은 주로 흥식호흡(costal breathing)을 사용 하지만 남성은 주로 복식호흡(abdominal breathing)을 사용하 여 구어 및 비구어 발화 시 다른 호흡생리를 사용한다고 했다. 연장모음을 이용하여 지속시간 및 기류량의 성차를 비교분석 한 Kim(2014)과 Zraick et al.(2012) 등 다수의 선행연구가 남성 군의 측정치가 여성군보다 유의하게 더 높았다고 보고하여 이 를 뒷받침해주고 있다.

기류량과 관련된 측정치 네 개가 모두 남성군이 여성군보다 더 높은 수치를 보였다. 최대흡기량은 유의한 차이를 보이지 않 았으나 최대호기량과 호기체적, 흡기체적은 유의하게 남성군이 더 높았다. 이는 Lewandowski et al.(2018)도 평균 29세의 젊 은 성인 남성 25명, 여성 25명의 문단낭독 시 공기역학적 특성 을 비교한 결과 남성이 유의하게 더 높은 발화 시 기류량을 보 였다고 한 결과와 일치한다. 이들은 남성이 더 높은 기류량을 보인 것은 남성의 기도(airway) 직경이 더 크기 때문에 더 많은 기류량을 확보하고 사용하는 것으로 설명했다.

모음연장 및 문단낭독 시 공기역학적 특성을 연령별, 성별로 비교분석한 Goozée et al.(1998)은 대부분의 선행연구와 달리 기류 관련 측정치가 성별간 유의한 차이를 보이지 않았다고 보 고했다. 비록 연구결과가 성별 간 유의한 차이가 없는 것으로 나타났지만 이들은 대부분의 선행연구가 남성이 유의하게 더 높은 수치를 보이고 있음에 대하여 인정하고 있었다. 남성이 여 성보다 더 높은 기류량을 보이는 것은 해부생리학적 특성의 성 차에 기인한다고 했는데 남성은 여성보다 더 크고 긴 성대, 더 큰 공명강, 더 큰 호흡체적과 폐의 탄성을 갖고 있기 때문에 이 러한 차이가 나타난다고 했다. 그럼에도 불구하고 이들의 연구 가 선행연구와 다른 결과를 보인 것은 실험에 참여한 참여자의 수, 사용한 기자재의 차이 등 방법론상의 차이에도 원인이 있 고 피험자 간 편차가 크게 나타난 것도 한 원인이라고 했다. 이 와 같이 다수의 선행연구가 공기역학적 특성의 성별간 차이를 남성과 여성의 신체적 차이에 근거를 두어 설명하고 있다.

위에서 언급한 대로 문단낭독 시 기류량 관련 측정치 중 유 의한 성차를 보이지 않은 측정치는 최대흡기량이었다. 정상성인 여성 화자와 음성장애 성인 여성화자의 문단낭독 시 공기역학 적 측정치를 비교한 $\mathrm{Pyo}(2019 \mathrm{~b})$ 의 연구결과에서도 최대흡기량 은 두 집단 간의 유의한 차이가 나타나지 않았다. 문단낭독 시 흡기는 휴지(pause) 및 호흡단락(breath group)과 연관성이 깊
은데 이들은 비단 호흡생리의 일환으로 일어나는 것뿐 아니라 다양한 언어적 요소를 충족시키기 위해서도 사용된다. Wang et al.(2010)은 16명의 정상성인 남성 및 여성 참여자를 대상으 로 문단낭독 및 자발화 시 호흡단락에 대해 분석한 실험을 통 해 문단낭독 시 호흡단락의 지속시간이나 호흡단락 사이의 휴 지시간, 흡기 지속시간은 호흡뿐 아니라 운동조정능력, 인지적 노력의 영향을 받을 수도 있다고 했다. Yoo \& Shin(2019)도 발 화 중 관찰되는 휴지는 단지 호흡만을 위한 것이 아니고 하나의 발화 전략으로 종종 사용된다고 했다. 일반적으로 정상성인 화 자는 휴지 시 흡기를 할 때 휴지 후 발화량에 따라 그 양을 조 절한다. 특히 본 연구는 발화내용이 정해져 있는 문단낭독을 사 용했고 실험 전에 문단을 묵독하도록 했기 때문에 어느 부분에 서 휴지를 둘 것이고 이후 발화를 어느 정도 유지할지를 대략 판단 혹은 계획할 수 있었다. 이러한 계획은 본인의 호흡능력보 다는 의미단락, 구둣점 등과 같은 언어적 요소에 더 무게중심 을 두고 이루어진다. 이러한 점은 성별에 따라 달라질 요인이 아니므로 흡기와 관련된 두 측정치에서 유의한 차이가 나타나 지 않았던 것으로 판단할 수 있다.

Jiang \& Maytag(2014)는 공기역학 측정치는 성대의 생체역 학을 반영하기 때문에 음성을 평가할 때 매우 유용한 지표가 된다고 했다. 그러므로 임상현장에서는 환자 음성 분석 시 공기 역학적 평가를 기본평가도구로 사용하는데 현재는 모음연장을 유일한 발화과제로 사용하는 것이 일반적이다. 그러나 Thiel et al.(2019)은 과제가 모음연장인지 연속발화인지에 따라 공기역 학적 음성효율(aerodynamic voice efficiency) 검사결과가 유 의한 차이를 보인다고 했다. 이와 같이 모음연장 과제만으로 일 상대화에서의 공기역학적 특성을 유추하는 것은 잘못된 해석 을 불러올 수 있으므로 공기역학적 평가 시 문단낭독과 같은 연속발화도 과제에 포함시켜야 한다. 공기역학적 평가 시 연장 모음의 측정치에서 남녀간의 폐활량 차이로 인해 남녀간 차이 가 나타난다는 것은 널리 알려져 있으나 문단 낭독 시에도 같 은 차이가 나타나는지 객관적 데이터를 이용해 검증하려고 한 연구는 아직 많지 않다. 본 연구는 성별에 따라 문단낭독 시 공 기역학적 특성에서 유의한 차이가 나타나는지를 특히 기기를 활용해 객관적으로 분석했다는 데 의의를 둘 수 있다. 그러나 결과를 일반화시키기에는 연구참여자 수가 부족하고 청년층만 을 대상으로 했으므로 추후 아동층 혹은 노인층을 위한 연구 도 이어져야 한다. 이를 통해 보다 더 다양한 범위와 측면에서 음성장애 환자의 음성과 음성산출 방법을 분석하고 음성장애 환자의 호흡지지 중재 시 성별 등 개인차를 좀 더 적극적으로 고려해야 한다.

중심 단어 : 공기역학적 평가·기류량-지속시간·성차· 문단낭독. 


\section{Ethical Statement}

This study was approved by the Institutional Review Board of the Chosun University (IRB No.: 2-1041055-AB-N-01-2-19-21).

\section{Acknowledgments N/A}

\section{Declaration of Conflicting Interests}

There are no conflict of interests.

\section{Funding}

N/A

\section{ORCID iD}

Hwa-Young Pyo

\section{REFERENCES}

Dastolfo, C., Gartner-Schmidt, J., Yu, L., Carnes, O., \& Gillespie, A. I. (2016). Aerodynamic outcomes of four common voice disorders: Moving toward disorder-specific assessment. Journal of Voice, 30(3), 301-307.

Ferrand, C. T. (2012). Voice Disorders: Scope of Theory and Practice. Upper Saddler River, NJ: Pearson Higher Education Inc.

Gartner-Schmidt, J. L., Hirai, R., Dastolfo, C., Rosen, C. A., Yu, L., \& Gillespie, A. I. (2015). Phonatory aerodynamics in connected speech. The Laryngoscope, 125(12), 2764-2771.

Gerratt, B. R., Kreiman, J., \& Garellek, M. (2016). Comparing measures of voice quality from sustained phonation and continuous speech. Journal of Speech, Language, and Hearing Research, 59(5), 994-1001.

Goozée, J. V., Murdoch, B. E., Theodoros, D. G., \& Thompson, E. C. (1998). The effects of age and gender on laryngeal aerodynamics. International Journal of Language and Communication Disorders, 33(2), 221-238.

Han, J. Y., Lee, O. B., \& Shim, L. S. (2008). The study of breath group based on oral airflow in reading by healthy speakers. Speech Sciences, 15(4), 135-146.

Hodge, M. M. \& Rochet, A. P. (1989). Characteristics of speech breathing in young women. Journal of Speech and Hearing Research, 32(3), 466480.

Jiang, J. J. \& Maytag, A. L. (2014). Aerodynamic measures of glottal function: What extra can they tell us and how do they guide management? Current Opinion in Otolaryngology and Head and Neck Surgery, 22(6), 450-454.

KayPENTAX. (2008). Phonatory Aerodynamic System (PAS) Model 6600.

Lincoln Park, NJ: KayPENTAX Co.

Kim, H. H. (2017). Neurogenic speech and language disorder. In Sim, H. S. Kwon, M. S., Kim, S. J., Kim, Y. T., Kim, J. M., Kim, J. S., et al. (3rd ed.) Introduction to Communication Disorders (pp. 167-196). Seoul: Hakjisa.

Kim, J. (2014). Korean adult normative data for the KayPENTAX Phonatory Aerodynamic System Model 6600. Phonetics and Speech Sciences, 6(1), 105-117.

Lewandowski, A., Gillespie, A. I., Kridgen, S., Jeong, K., Yu, L., \& GartnerSchmidt, J. (2018). Adult normative data for phonatory aerodynamics in connected speech. The Laryngoscope, 128(4), 909-914.

Manifold, J. A. \& Murdoch, B. E. (1993). Speech breathing in young adults: Effect of body type. Journal of Speech and Hearing Research, 36(4), 657-671.

Maryn, Y. \& Roy, N. (2012). Sustained vowels and continuous speech in the auditory-perceptual evaluation of dysphonia severity. Jornal da Sociedade Brasileira de Fonoaudiologia, 24(2), 107-112.

Moon, T. H., Shim, M. R., Hwang, Y. S., Kim, G. J., Lee, D. H., \& Sun, D. I. (2019). Aerodynamic characteristics of voice disorders (polyp, cyst) before and after laryngeal micro surgery: Focus on running speech. Journal of the Korean Society of Laryngology, Phoniatrics and Logopedics, 30(2), 95-100.

Pyo, H. Y. (2019a). Aerodynamic characteristics of young and elderly adult patients with voice disorders during continuous speech. The Journal of the Korea Contents Association, 19(12), 270-278.

Pyo, H. Y. (2019b). Comparison of aerodynamic characteristics in female adults with normal function and with functional voice disorders during reading paragraph tasks. Audiology and Speech Research, 15(4), 311319.

Schaeffer N. (2017). Pre- and poststimulation study on the phonatory aerodynamic system on participants with dysphonia. Journal of Voice, 31(2), 254.e1-254.e9.

Thiel, C., Yang, J., Crawley, B., Krishna, P., \& Murry, T. (2019). Aerodynamic characteristics of syllable and sentence productions in normal speakers. Journal of Voice, 33(3), 297-301.

Wang, Y. T., Green, J. R., Nip, I. S., Kent, R. D., Kent, J. F., \& Ullman, C. (2010). Accuracy of perceptually based and acoustically based inspiratory loci in reading. Behavior Research Methods, 42(3), 791-797.

Yoo, D. \& Shin, J. (2019). A realization of pauses in utterance across speech style, gender, and generation. Phonetics and Speech Sciences, 11(2), 3344.

Zraick, R. I., Smith-Olinde, L., \& Shotts, L. L. (2012). Adult normative data for the KayPENTAX Phonatory Aerodynamic System Model 6600. Journal of Voice, 26(2), 164-176. 


\section{APPENDICES}

\section{Appendix 1. Reading Material}

우리나라의 가을은 참으로 아름답다. 무엇보다도 산에 오를 땐 더욱 더 그 빼어난 아름다움이 느껴진다. 쓰다듬어진 듯한 완만 함과 깎아놓은 듯한 뾰족함이 어우러진 산등성이를 따라 오르다 보면 절로 감탄을 금할 수가 없게 된다. 붉은색, 푸른색, 노란색 등의 여러 가지 색깔이 어우러져 타는 듯한 감동을 주며 나아가 신비롭기까지 하다. 숲속에 누워서 하늘을 바라보라. 쌍쌍이 짝지 어있는 듯한 흰 구름, 높고 파란 하늘을 쳐다보고 있노라면 과연 옛부터 가을을 천고마비의 계절이라 일컫는 이유를 알게 될 것 만 같다.

\section{Appendix 2. Descriptions of Aerodynamic Measures in 'Running Speech' Program*}

\begin{tabular}{|c|c|}
\hline 측정치 & 설 명 \\
\hline 발성지속시간(phonation time) & 전체 발화 중 성대진동을 동반하여 산출된 구간의 지속시간 \\
\hline 호기지속시간(expiratory airflow duration) & $\begin{array}{l}\text { 전체 발화 중 양(+)의 기류량을 나타나는 구간의 지속시간. 발화 중 호기가 일어난 } \\
\text { 전체시간을 나타냄. }\end{array}$ \\
\hline 흡기지속시간(inspiratory airflow duration) & $\begin{array}{l}\text { 전체 발화 중 음(-)의 기류량을 나타나는 구간의 지속시간. 발화 중 흡기가 일어난 } \\
\text { 전체시간을 나타냄. }\end{array}$ \\
\hline 최대호기량(peak expiratory airflow) & 전체 발화의 호기율 중 가장 높은 혹은 정점의 측정치 \\
\hline 최대흡기량(peak inspiratory airflow) & 전체 발화의 흡기율 중 가장 높은 혹은 정점의 측정치 \\
\hline 호기체적(expiratory volume) & 전체 발화 중 양(+)의 기류량의 총합 \\
\hline 흡기체적(inspiratory volume) & 전체 발화 중 음(-)의 기류량의 총합 \\
\hline 총지속시간(total duration) ${ }^{\dagger}$ & 호기지속시간과 흡기지속시간의 합. 전체발화시간을 의미함. \\
\hline
\end{tabular}

*Source: KayPENTAX (2008). Phonatory Aerodynamic System (PAS) Model 6600. Lincoln Park, NJ, USA.

†본 연구자가 추가로 계산한 측정치임 